\title{
Canthium parviflorum Leaves: Antioxidant Activity in Food and Biological Systems, pH, and Temperature Stability
}

\author{
Vanitha Reddy Palvai, Sowmya Mahalingu, and Asna Urooj \\ Department of Studies in Food Science and Nutrition, University of Mysore, Mysore 570006, India \\ Correspondence should be addressed to Asna Urooj; asnaurooj@foodsci.uni-mysore.ac.in
}

Received 12 January 2014; Accepted 16 March 2014; Published 10 April 2014

Academic Editors: L. Corazzi, D. Junbao, and Y. Liu

Copyright ( 2014 Vanitha Reddy Palvai et al. This is an open access article distributed under the Creative Commons Attribution License, which permits unrestricted use, distribution, and reproduction in any medium, provided the original work is properly cited.

Canthium parviflorum leaves were analyzed for their proximate and phytochemical composition. The leaves were extracted with methanol (ME) and analyzed for antioxidant activity by radical scavenging method, reducing power, ferric reducing capacity, and in vitro inhibition of Fenton's reagent induced oxidation in oil emulsion and microsomes. In addition, the effect of high temperature $\left(100^{\circ} \mathrm{C}, 15\right.$ and $\left.30 \mathrm{~min}\right)$ and $\mathrm{pH}(4.5,7$, and 9$)$ on the antioxidant activity of $\mathrm{ME}$ was investigated. The leaves were rich in polyphenols, flavonoids $\beta$-carotene, glutathione, $\alpha$-tocopherol, and ascorbic acid. The ME exhibited varying degree of antioxidant activity in a dose dependent manner. The RSA was $68 \%-500 \mu \mathrm{g}$. Reducing potency was 0.34 and FRAP was 1.377. Canthium exhibited greater inhibition of oxidation in microsomes $(73 \%)$ than in the oil emulsion $(21 \%)$. Heat treatment resulted in reduction of radical scavenging activity of extract from $68 \%$ to $40 \%$. At pH 4.5 and 7 methanol extract exhibited some percent of antioxidant activity which ranged between 18 and 32\%. Data indicates Canthium as a good source of antioxidants and methanol extract exhibited good antioxidant activity.

\section{Introduction}

In recent years, secondary plant metabolites with unknown pharmacological activities have been extensively investigated as a source of medicinal agents. Natural antioxidants present in food and other biological materials have attracted considerable interest because of their presumed safety and potential nutritional and therapeutic effects. The increasing interest in the search for natural replacements for synthetic antioxidants has led to the antioxidant evaluation of a number of plant sources [1] especially spices and herbs [2]. Screening active compounds from plants has led to the discovery of new medicinal drugs which have efficient protection and treatment roles against various degenerative diseases. In recent years, a large number of plants have been screened as a viable source of natural antioxidants such as tocopherol, vitamin C, carotenoids, and phenolic compounds which are responsible for maintenance of health $[3,4]$.

At present time, medicinal plants as rich source of natural bioactive components are given priority to study their antioxidant activity and explore their utilization in treatment of diabetes mellitus, dyslipidemia, and cardiovascular diseases. Our team has explored some medicinal plants, namely, Moringa oleifera [5], Morus indica [6], Aegle marmelos [7], Raphanus sativus [8], and Psidium guajava [9], for their antioxidant activity and stability. Before exploring a medicinal plant, there is a need to analyze the plant for its phytochemical composition, its antioxidant activity, and its stability to explore the plant as nutraceutical.

Canthium parviflorum is a shrubby and woody plant found throughout the Western Ghats. Canthium as herbal medicine is used for the treatment of diabetes among major tribal groups in South India $[10,11]$. Though the ethnomedicinal importance of this plant is known, the phytochemical basis for such kind of medicinal property is not known. However, complete information on the phytochemical composition and its antioxidant stability is not very well studied. In the present experiment the proximate and phytochemical composition, antioxidant potency, and stability of the Canthium parviflorum are reported. 


\section{Materials and Methods}

2.1. Plant Material. Canthium parviflorum (CP) leaves were collected from Western Ghats of Karnataka. The sample was identified by Dr. Janardhan, Department of Studies in Botany, University of Mysore, and voucher specimen was retained in the laboratory for future reference. The collected leaves were washed, dried in the oven overnight at $50^{\circ} \mathrm{C}$, powdered, passed through 60 mesh, and stored at $4^{\circ} \mathrm{C}$ till further use.

2.2. Proximate Composition. In the dry powder, moisture content was determined by using moisture analyzer (Metler Toledo MJ33, India Pvt. Ltd.). Fat, protein, ash, total fiber (soluble and insoluble fiber), iron, calcium, and phosphorus were estimated as per the AOAC methods [12].

2.3. Determination of Phytochemical Components. In the dry sample, different antioxidant components were estimated using standard methods. Ascorbic acid was determined according to the titrimetric method using 2,6-dichlorophenol-indophenol dye [13]. $\alpha$-Tocopherol was extracted by direct saponification of dried sample and estimated based on formation of a red complex from reaction of $\alpha, \alpha^{\prime}$-bipyridyl with ferrous ion due to reduction of ferric ion by tocopherol [5]. $\beta$-Carotene was quantified by open column chromatography, followed by measuring the absorbance of elute at $450 \mathrm{~nm}$ against standard $\beta$-carotene [13]. Reduced glutathione was determined based on the development of a yellow compound due to reaction of DTNB (5, 5-dithio (bis) nitrobenzoic acid) with compounds containing sulphhydryll groups [14]. Total phenols were extracted from a weighed portion $(1 \mathrm{~g})$ of dried sample with $5 \mathrm{~mL}$ of $1.2 \mathrm{M} \mathrm{HCl}$ in $50 \%$ aqueous methanol for $2 \mathrm{~h}$ and with $70 \%$ acetone shaken for $2 \mathrm{~h}$ and analyzed by Folin-Ciocalteu micromethod [15]. Results were expressed as $\mathrm{mg}$ or $\mathrm{g}$ of gallic acid equivalent. The flavonoid content was determined by pharmacopoeia method [16] using rutin as a reference compound.

2.4. Extraction of Antioxidants. A $15 \mathrm{~g}$ sample was extracted with $50 \mathrm{~mL}$ methanol (CP-ME) for $6 \mathrm{~h}$ in a mechanical shaker. The extracts were filtered and filtrates were evaporated at $40^{\circ} \mathrm{C}$ under reduced pressure to dryness in a rotary evaporator (Superfit, India). The residue of each extract was stored in airtight container at $4^{\circ} \mathrm{C}$ till further use.

2.5. Radical Scavenging Activity. The ability of CP methanol extract (CP-ME) to scavenge 2,2-diphenyl-1-picrylhydrazyl $(\mathrm{DPPH})$ radicals was determined according to the method of Blois, 1958 [17].

2.6. Reducing Power Assay. The ability of CP-ME to reduce iron(III) to iron(II) was determined as per Yildirim et al., $2003[18]$.

2.7. Ferric Reducing Antioxidant Power (FRAP). Measurement of ferric reducing antioxidant power of the CP-ME was carried according to the procedure given by Benzie and Strain, 1999 [19].
2.8. Inhibition of Lipid Oxidation. The antioxidant activity of the CP-ME (300-500 $\mu \mathrm{g})$ was determined in an edible oil emulsion and liver microsomes by modified method of TBARS (thiobarbituric acid reactive substances) [20]. The method determines the resistance of lipid or lipid emulsions to oxidation in the presence of the antioxidant. The malondialdehyde (MDA) or TBARS assays have been used extensively since the 1950s to estimate the peroxidation of lipids in membrane and biological systems.

2.8.1. In Oil Emulsion. Five grams of oil (sunflower) was weighed and an emulsion was prepared in phosphate buffer of $0.01 \mathrm{M}, 7 \mathrm{pH}$. To different concentrations $(300-500 \mu \mathrm{g})$ of extracts, $300 \mu \mathrm{L}$ of emulsion and $450 \mu \mathrm{L}$ of Fenton's reagent were added and volume was made up to $2 \mathrm{~mL}$ and incubated at $50^{\circ} \mathrm{C}$ for 6 hrs. A control was run without extract. After incubation, $1 \mathrm{~mL}$ of thiobarbituric acid (TBA) was added and heated in boiling water bath for $30 \mathrm{~min}$ and cooled immediately. The inhibition of lipid peroxidation in sun flower oil was determined by TBARS, in which the secondary oxidation products (TBARS, expressed as MDA equivalents) formed by oxidation of oil were determined by measuring the absorbance at $532 \mathrm{~nm}$ [21].

2.8.2. In Microsomes. A healthy male adult rat was obtained from the Central animal house, Department of Zoology, University of Mysore, after availing clearance from the University Animal Ethics Committee of University of Mysore (number MGZ/2620/2011-12; dated January 31, 2012).

2.8.3. Preparation of Microsomes. The procedure described here is partially modified from that reported by Shapiro and Rodwell, 1971 [22]. The rat was sacrificed and liver was immediately removed from the rat and placed in cold triethanolamine $\mathrm{HCl}$ buffer $\left(0-4^{\circ} \mathrm{C}\right)$ at $\mathrm{pH}$ 7.4. The liver was immediately removed and placed in cold buffer $\left(0-4^{\circ} \mathrm{C}\right)$ at $\mathrm{pH}$ 7.4. The buffer contained $0.1 \mathrm{M}$ triethanolamine $\mathrm{HCl}, 0.02 \mathrm{M}$ EDTA, and $2.0 \mathrm{mM}$ dithiothreitol. The liver was thoroughly chilled, blotted, and weighed. The tissue was minced with scissors and homogenized with $3.5 \mathrm{~mL}$ of buffer/g of tissue. The homogenization was done with six strokes of a smoothwalled, glass Remi homogenizer with a loose-fitting Teflon pestle ( $0.5 \mathrm{~mm}$ radial clearance). The homogenate was centrifuged for $10 \mathrm{~min}$ at $12,000 \mathrm{~g}$ to remove cell debris and mitochondria. Then, the supernatant solution was carefully removed to prevent contamination with mitochondria and recentrifuged for $10 \mathrm{~min}$ at $12,000 \mathrm{~g}$ to ensure removal of mitochondria; it was then centrifuged at $60,000 \mathrm{~g}$ for $60 \mathrm{~min}$. The $60,000 \mathrm{~g}$ microsomal pellet was then rinsed with buffer and frozen in a freezer $\left(-20^{\circ} \mathrm{C}\right)$. Frozen microsomes were resuspended in $0.1 \mathrm{M}$ triethanolamine buffer, $\mathrm{pH} 7.4$, containing $0.02 \mathrm{M}$ EDTA and $10 \mathrm{mM}$ dithiothreitol and allowed to stand $60 \mathrm{~min}$ packed in ice; they were then centrifuged at $60,000 \mathrm{~g}$ for $45 \mathrm{~min}$. The resuspended microsomes to be used for the assay were diluted with buffer to give a protein concentration of $5-10 \mathrm{mg} / \mathrm{mL}$.

To an aliquot of liver microsomes ( $1 \mathrm{mg}$ protein concentration), Fenton's reagent and methanol extract of Canthium 
TABle 1: Proximate, phytochemical, and antioxidant composition of Canthium parviflorum.

\begin{tabular}{lccc}
\hline Parameter (\%-dry basis) & (\%-dry basis) & Phytochemicals & (\%-dry basis) \\
\hline Moisture & $9.33 \pm 0.14$ & Polyphenols $^{*}$ & $1.279 \pm 0.32$ \\
Protein & $5.345 \pm 0.57$ & Flavonoids* $^{*}$ & $2.443 \pm 0.811$ \\
Fat & $7.30 \pm 0.14$ & Glutathione** $^{*}$ & $311.55 \pm 25$ \\
Soluble fibre & $4 \pm 0.57$ & $\alpha$-Tocopherol $^{*}$ & $164.6 \pm 22.1$ \\
Insoluble fibre & $20 \pm 0.15$ & Tannins $^{*}$ & $605.04 \pm 0.025$ \\
Ash & $9.67 \pm 0.01$ & $\beta$-carotene $^{* * *}$ & $1060.0 \pm 0.6$ \\
Calcium* & $983.15 \pm 9$ & Alkaloids $^{*}$ & $400.0 \pm 0.06$ \\
Phosphorous $^{*}$ & $380.15 \pm 9.33$ & Total saponins & $0.200 \pm 0.04$ \\
Iron $^{*}$ & $21.97 \pm 0.54$ & Steroidal saponins & $0.148 \pm 0.051$ \\
& & Vitamin C (dry basis) & $0.141 \pm 0.001$ \\
& & Vitamin C (Fresh basis) & $0.0228 \pm 0$ \\
\hline
\end{tabular}

${ }^{*} \mathrm{mg} / 100 \mathrm{~g} ;{ }^{* *} \mathrm{mmol} / 100 \mathrm{~g} ;{ }^{* * *} \mu \mathrm{g} / 100 \mathrm{~g}$ dry basis. Values are mean of triplicates.

$(300-500 \mu \mathrm{g})$ were added and incubated at $50^{\circ} \mathrm{C}$ for $2 \mathrm{hrs}$. After incubation, $1 \mathrm{~mL}$ of TCA (10\%) and $1 \mathrm{~mL}$ of TBA were added and heated in boiling water bath $(15 \mathrm{~min})$ and cooled in ice bath immediately. After cooling, $2 \mathrm{~mL}$ of butanol was added and the pink color developed was read at $535 \mathrm{~nm}$. A control was run without plant extract [23]:

Antioxidant activity \%

$$
=\frac{\text { Absorbance of control }- \text { Absorbance of sample }}{\text { Absorbance of control }} \times 100 \text {. }
$$

2.9. Heat and $p H$ Stability. The CP-ME was heated in a boiling water bath for $15 \mathrm{~min}$ and the residual antioxidant activity was determined using DPPH, as described previously. For $\mathrm{pH}$ stability, the CP-ME was incubated for $72 \mathrm{~h}$ at $\mathrm{pH} 4.5$, 7 , and 9 and the residual antioxidant activity was determined during the incubation period at different time intervals (0 min, $30 \mathrm{~min}$, and 24, 48, and $72 \mathrm{~h}$ ) using RSA method [24].

\section{Statistical Analysis}

Mean values of triplicates $(n=3)$ were subjected to one way ANOVA and Tukey's multiple comparison tests using SPSS software (version 11) $(P<0.05)$.

\section{Results}

4.1. Proximate and Phytochemical Composition. Canthium parviflorum was found to be a good source of nutrients, $\beta$-carotene, $\alpha$-tocopherol, ascorbic acid, and phytochemicals, namely, total polyphenols, glutathione, and flavonoids (Table 1).

4.2. Radical Scavenging Activity (RSA). The \% radical scavenging activity of CP was measured at 100, 200, 300, 400, and $500 \mu \mathrm{g}$ and the activity was in a dose dependent manner (Figure 1). From the figure, it can be observed that the scavenging activity ranged between $12.5 \pm 0.4$ and $68.65 \pm$ $0.2 \%$. The activity increased significantly $(P \leq 0.05)$ from 100

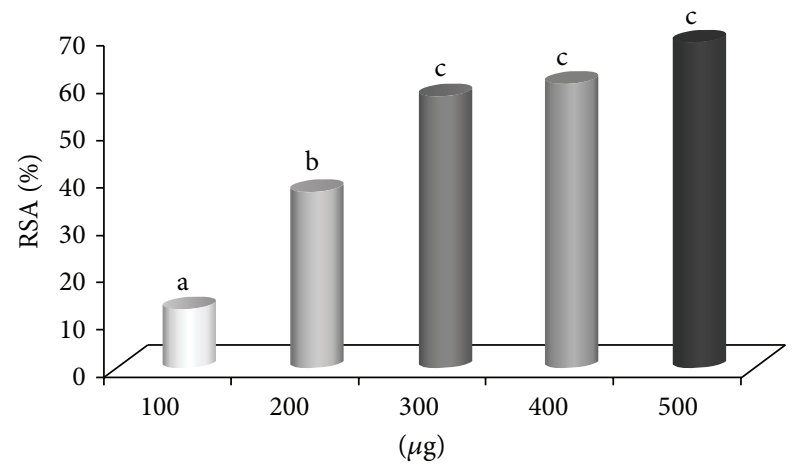

FIGURE 1: Radical scavenging activity (RSA) by methanol extract of Canthium parviflorum. $n=3$; bars with different alphabets, a, b, c, $\ldots$, differ significantly $(P \leq 0.05)$.

to $300 \mu \mathrm{g}$ and no significant difference was observed between 300 and $400 \mu \mathrm{g}$ (57 and 60\%) and at $500 \mu \mathrm{g}$ the activity was significantly $(P \leq 0.05)$ high, that is, $68 \%$.

4.3. Reducing Power. The electron donating capacity was measured at 100-500 $\mu$ g (Figure 2). The reducing power of the samples was dose dependent which ranged between $0.132 \pm$ 0.015 and $0.339 \pm 0.001$.

4.4. Ferric Reducing Antioxidant Power (FRAP). The change in absorbance at $593 \mathrm{~nm}$ owing to the formation of a blue colored Fe(II)-tripyridyl triazine compound from colorless oxidized Fe(III) is formed by the action of electron donating antioxidants. This represents an electron exchange reaction. It showed high reducing power at lower concentration $(100 \mu \mathrm{g})$ and increased with the concentration (Figure 3). The FRAP value of CP-ME ranged between $0.468 \pm 0.09$ and $1.377 \pm 0.07$.

4.5. Inhibition of Lipid Peroxidation. The inhibition of oxidation in oil emulsion and microsomes was measured at 300 , 400, and $500 \mu \mathrm{g}$ and the CP-ME exhibited the activity in dose dependent manner in both the substrates. The sample exhibited higher rate of oxidation inhibition in microsomes 


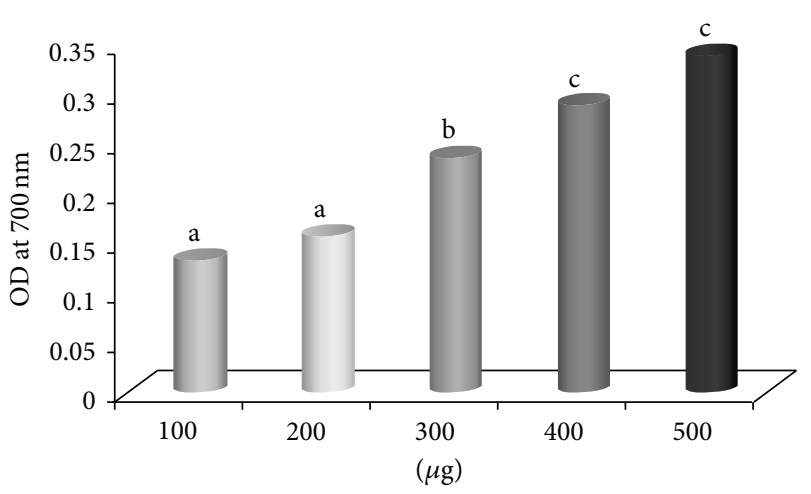

FIGURE 2: Reducing power by methanol extract of Canthium parviflorum. $n=3$; bars with different alphabets, $a, b, c, \ldots$, differ significantly $(P \leq 0.05)$.

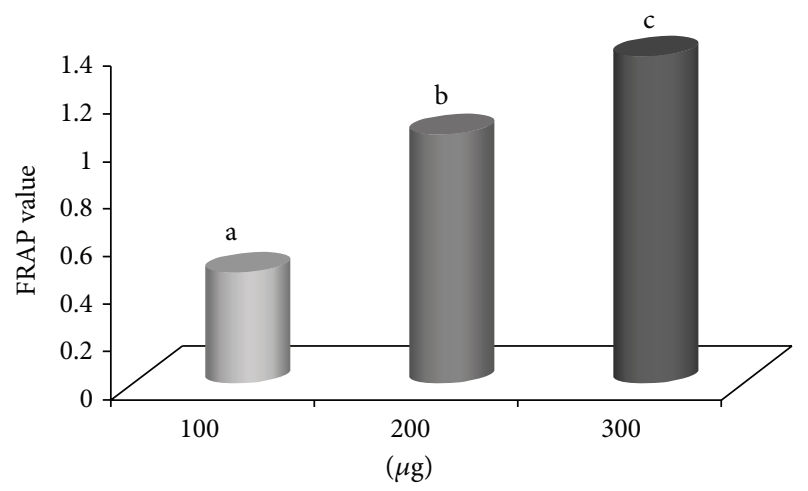

FIGURE 3: Ferric reducing antioxidant power (FRAP) by methanol extract of Canthium parviflorum. $n=3$; bars with different alphabets, a, b, c, ... differ significantly $(P \leq 0.05)$.

(76.22 $\pm 12.38-300 \mu \mathrm{g} ; 94.95 \pm 4.44-400 \mu \mathrm{g}, 96.43 \pm 3.93-$ $500 \mu \mathrm{g})$ than in the oil emulsion $(9.15 \pm 0.6-300 \mu \mathrm{g} ; 14.66 \pm$ $3.73-400 \mu \mathrm{g}, 24.75 \pm 1.11-500 \mu \mathrm{g}$ ) (Figure 4).

4.6. Stability of CP Extracts to High Temperature $\left(100^{\circ} \mathrm{C} ; 15\right.$ and $30 \mathrm{~min}$ ). It is well known that many factors such as sample concentration, temperature, and $\mathrm{pH}$ of the media and processing treatments influence the antioxidant activity. Radical scavenging activity of the heat treated CP-ME is shown in Figure 5 and heat treatment has resulted in a decline in scavenging activity. After 15 min of heat treatment, slight decline in the activity was observed at all the concentrations and by the end of $30 \mathrm{~min}$ the activity increased. However, the percent activity at $30 \mathrm{~min}$ was significantly $(P \leq 0.05)$ lower than the initial value, that is, $0 \mathrm{~min}$.

4.7. Stability of CP Extract to Different $p H$. The antioxidant stability of sample extract to different $\mathrm{pH}(4.5,7$, and $9 \mathrm{pH})$ was analyzed by radical scavenging activity (Figures 6(a) and 6(b)). The influence of $\mathrm{pH} 4.5$ on the stability of CP-ME is shown in Figure 6(a). At pH 4.5, a significant decrease $(P \leq$ $0.05)$ in radical scavenging activity was observed from 200 to $500 \mu \mathrm{g}$. The maximum scavenging activity observed was

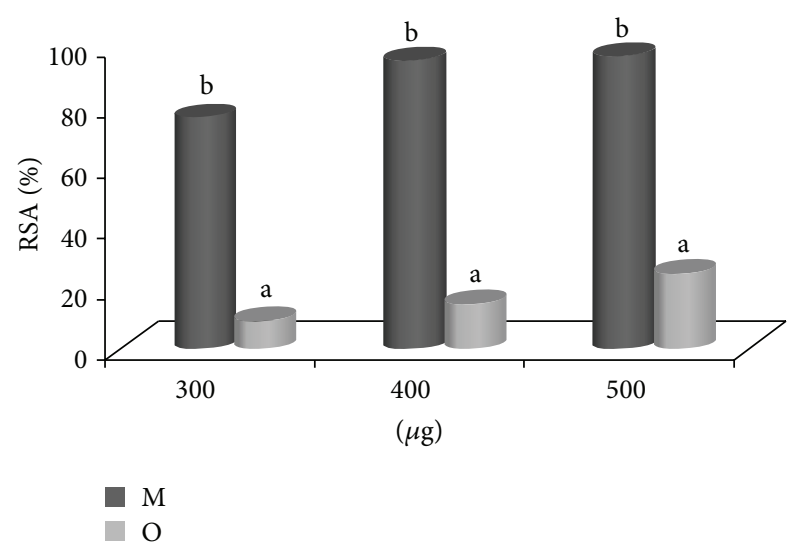

FIgURE 4: Inhibition of oxidation in biological and food substrates by methanol extract of Canthium parviflorum. $n=3$; M: microsomes; O: oil emulsion; bars with different alphabets, $a, b, c, \ldots$, differ significantly $(P \leq 0.05)$.

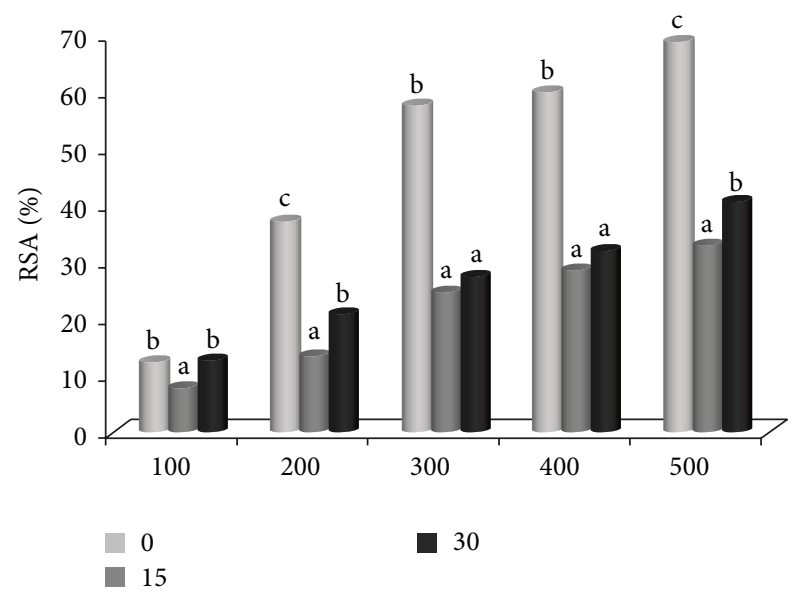

FIGURE 5: Stability of Canthium parviflorum methanol extract to high temperature $\left(100^{\circ} \mathrm{C} ; 15\right.$ and $\left.30 \mathrm{~min}\right) . n=3$; bars with different alphabets, a, b, $c, \ldots$, differ significantly $(P \leq 0.05)$.

$20 \%-500 \mu \mathrm{g}$ by the end of $72 \mathrm{hrs}$. At $\mathrm{pH} 7$, by the end of $72 \mathrm{hrs}$, a significant increase $(P \leq 0.05)$ in RSA was observed at $100-300 \mu \mathrm{g}$ and at 400 and $500 \mu \mathrm{g}$ the RSA decreased from 24 to $72 \mathrm{hrs}$; however, the decline in RSA was not significant. At pH 9, none of the extracts exhibited RSA and the absorbance was more than that of control.

\section{Discussion}

Natural antioxidants that occur in all parts of plants include carotenoids, vitamins, phenols, flavonoids, dietary glutathione, and endogenous metabolites. Such antioxidants are peroxide decomposers, enzyme inhibitors, and synergists which act as second line defense antioxidants $[25,26]$. On the whole, these phytochemicals and antioxidants bestow high medicinal value to Canthium.

Results presented here clearly indicate that the methanol extract of CP with some percentage of polyphenols exhibited 


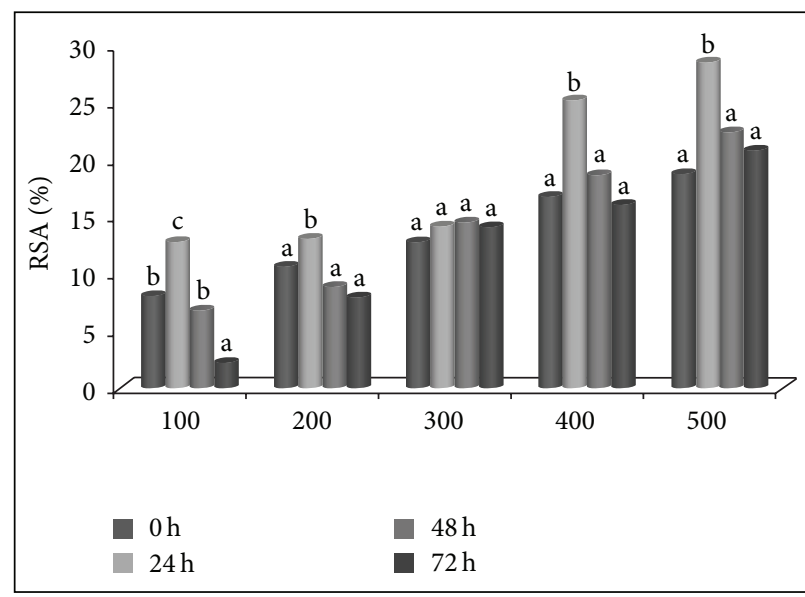

(a)

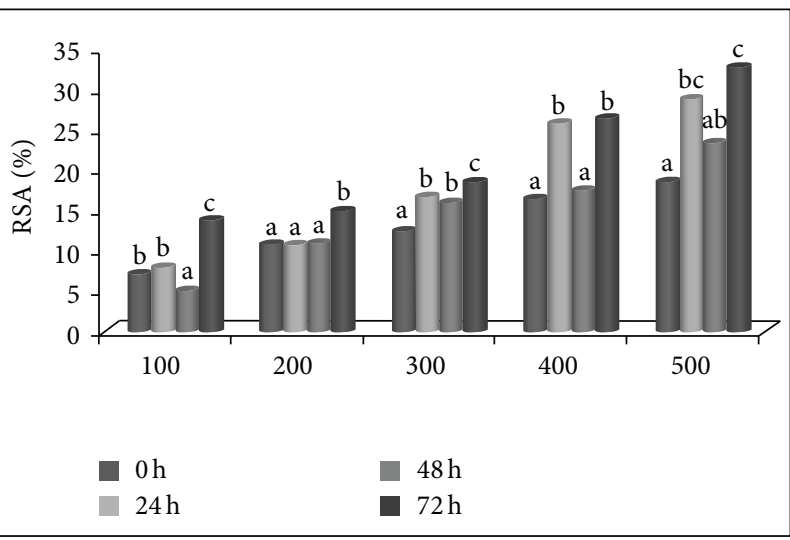

(b)

FIGURE 6: (a) Stability of antioxidants in Canthium parviflorum to $\mathrm{pH} 4.5$ by radical scavenging activity. $n=3$; bars with different superscripts $\mathrm{a}, \mathrm{b}, \mathrm{c}, \ldots$ differ significantly $(P \leq 0.05)$. (b) Stability of antioxidants in Canthium parviflorum to $\mathrm{pH} 7$ by radical scavenging activity. $n=3$; bars with different superscripts $a, b, c, \ldots$ differ significantly $(P \leq 0.05)$.

antioxidant activity in different in vitro models. In the process of oxidation, free radicals are considered to play a cardinal role in numerous chronic pathologies. The radical scavenging activity of $\mathrm{CP}$ is comparatively less than the antioxidant activity of few other medicinal plants studies in our laboratory such as Aegle marmelos [7], Moringa oleifera [5], and Morus indica [27].

The reducing power of a compound is related to its electron transfer ability and may therefore serve as a significant indicator of its potential antioxidant activity [27]. The presence of reducing agents (i.e., antioxidants) causes the reduction of the $\mathrm{Fe}^{3+}$-ferricyanide complex to the ferrous form. Therefore, measuring the formation of Perl's Prussian blue at $700 \mathrm{~nm}$ can monitor the $\mathrm{Fe}^{2+}$ concentration. The ability of CP methanol extract to reduce iron(III) to iron(II) is inferior to the standard (ascorbic acid-0.973), Aegle marmelos [7], Morus indica [6], and superior to Raphanus sativus [8]. Accordingly, CP might contain higher amounts of reductone, which could react with free radicals to stabilize and block radical chain reactions. Phytochemicals such as flavonoids, vitamin $\mathrm{C}$, and glutathione directly interact with radicals like $\mathrm{O}_{2}{ }^{-}, \mathrm{OH}^{*}$ and scavenge many free radicals like $\mathrm{O}_{2}{ }^{\circ}, \mathrm{OH}^{*}$, and various lipid hydroperoxides and may help to detoxify many inhaled oxidizing pollutants like ozone, $\mathrm{NO}_{2}$, and free radicals in cigarette smoke in respiratory tract [28].

Lipid oxidation is a process in which PUFA undergoes oxidative damage resulting in the formation of lipid derived radicals such as alkoxy and peroxyl radicals further causing membrane damage and cellular injury. Processed foods containing fats and oils oxidize slowly during storage; various oxidation products cause rancidity and deterioration of the sensory and nutritional property of the food products. In food and biological systems, antioxidants are capable of stabilizing or deactivating free radicals before they attack cells [29]. To protect the cells and organ systems of the body against reactive oxygen species, humans have evolved a highly sophisticated and complex antioxidant protection system that functions interactively and synergistically to neutralize free radicals [30]. Vitamin E scavenges peroxyl radicals' intermediates in lipid peroxidation and inhibits oxidation of PUFA present in cell membrane and LDL against lipid peroxidation. The polarity of phytochemicals plays a key role in exhibiting antioxidant role at lipid phase especially at unsaturation site, which influences the chain breaking reaction [29]. Here, CP antioxidants with high partition coefficient may be distributed hydrophobic compartments for the protection of lipids and other phytochemicals such as phenolic compounds also would have acted as reducing agent and inhibited the free radical generation against Fenton's reaction. Canthium was more effective in inhibiting the oxidation in microsomes compared to oil emulsion. These observations are similar to earlier results found in case of Morus indica [6] and Abrus precatorius [31]. Hence, the use of two lipid systems was helpful in studying the oxidative inhibition potency of different extracts in food and biological system.

Heat treatment for 15 min resulted in a decline in RSA of the $\mathrm{CP}$ extract while after $30 \mathrm{~min}$ an increase in activity was observed. This may be due to the activation of antioxidant components with prolonged heat treatment. This observation is in accordance with an earlier study from our lab on the effect of heat treatment on drumstick, mint, and carrot leaves extracts. These results indicate that thermal processing can induce the formation of novel compounds with antioxidant properties or improve the AOA of naturally occurring antioxidants [32]. In an another study, WE (water), ME (methanol), and EE (ethanol) extracts of Aegle marmelos $L$ were treatedat $100^{\circ} \mathrm{C}$ and WE showed maximum stability compared to ME and EE as measured by RSA after heat treatment [7] and similar results were found in case of Raphanus sativus [8] and Moringa oleifera [5]. 
The RS of methanol extracts at $\mathrm{pH} 4.5$ and 7 ranged between 18 and 32\%. At pH 9, no activity was observed at all the concentrations; this may be due to the structural denaturation of natural antioxidant components, and similar results were found in fenugreek seeds and ginger rhizome extracts [33], Aegle marmelos [7], Raphanus sativus [8], and Abrus precatorius [31] where samples exhibited better antioxidant activity at 4.5 and 7 , compared to $\mathrm{pH} 9$, whereas in case of the different extracts from cocoa by-products, the antioxidant activity was found to be higher at alkaline $\mathrm{pH}$ [34]. In an earlier study, it was observed that extracts from mint and carrot leaves showed higher antioxidant activity at pH 9 than $\mathrm{pH} 4.5$ [35]. These differences might be due to different samples used, various compounds being extracted in each case, and the method used to evaluate antioxidant potency.

\section{Conclusion}

Results of the present study reveal the antioxidant potency of Canthium parviflorum with good nutritional and phytochemical composition. The stability to heat indicates its scope for utilization in food and biological systems. Since methanol extract of Canthium did not exhibit good antioxidant activity at different $\mathrm{pH}$, further work is in progress on different solvents that can extract more antioxidants and exhibit better stability to different $\mathrm{pH}$. This study may help in promoting Canthium plant as a "nutraceutical" source.

\section{Conflict of Interests}

The authors declare that there is no conflict of interests regarding the publication of this paper.

\section{Acknowledgment}

The authors acknowledge UGC-IOE (Institute of Excellence) for providing financial assistance.

\section{References}

[1] A. Lugasi, J. Hóvári, K. V. Sági, and L. Bíró, “The role of antioxidant phytonutrients in the prevention of diseases," Acta Biologica Szegediensis, vol. 47, no. 1-4, pp. 119-125, 2003.

[2] N. Nakatani, "Antioxidants from spices and herbs," in Natural Antioxidants. Chemistry, Health Effects and Applications, pp. 6473, AOCS Press, Champaign, Ill, USA, 1997.

[3] D. Prakash, S. Suri, G. Upadhyay, and B. N. Singh, "Total phenol, antioxidant and free radical scavenging activities of some medicinal plants," International Journal of Food Sciences and Nutrition, vol. 58, no. 1, pp. 18-28, 2007.

[4] C. Kaur and H. C. Kapoor, "Antioxidants in fruits and vegetables-the millennium's health," International Journal of Food Science and Technology, vol. 36, no. 7, pp. 703-725, 2001.

[5] A. Urooj and P. V. Reddy, "Moringa oleifera: antioxidant properties and stability of various solvent extracts," International Journal of Pharmaceutical Science and Biotechnology, vol. 1, no. 1, pp. 1-6, 2010.
[6] P. V. Reddy and A. Urooj, "Proximate, phytochemical profile and antioxidant activity (in vitro and ex vivo) of Morus indica varieties," International Journal of Pharmaceutical Sciences and Research, vol. 4, no. 4, pp. 1626-1634, 2013.

[7] P. V. Reddy and A. Urooj, "Antioxidant properties and stability of Aegle marmelos leaves extracts," Journal of Food Science and Technology, vol. 50, no. 1, pp. 135-140, 2013.

[8] P. V. Reddy, S. Desai, F. Ahmed, and A. Urooj, "Antioxidant properties and stability of Raphanus sativus extracts," Journal of Pharmacy Research, vol. 3, no. 3, pp. 658-661, 2011.

[9] P. V. Reddy, N. Sahana, and A. Urooj, "Antioxidant activity of Aegle marmelos and Psidium guajava leaves," International Journal of Medicinal and Aromatic Plants, vol. 2, no. 1, pp. 155160, 2012.

[10] M. Ayyanar, K. Sankarasivaraman, and S. Ignacimuthu, "Traditional herbal medicines used or the treatment of diabetes among two major tribal groups in south Tamil Nadu, India," Ethnobotanical Leaflets, vol. 12, pp. 276-280, 2008.

[11] S. Chandra Kala, K. Mallikarjuna, and P. Arun, "Qualitative phyto chemical analysis of seed and leaf callus extracts of Canthium parviflorum Lam. Guntur District, Andhra, Pradesh," International Journal of Pharma and Bio Sciences, vol. 3, no. 4, pp. 177-182, 2012.

[12] AOAC, Official Methods of Analysis, AOAC International, Washington, DC, USA, 14th edition, 1984.

[13] S. Ranganna, Handbook of Analysis and Quality Control for Fruits and Vegetables Products, McGrow-Hill, New Delhi, India, 2nd edition, 1999.

[14] E. Beutler and B. M. Kelly, "The effect of sodium nitrite on red cell GSH,” Experientia, vol. 19, no. 2, pp. 96-97, 1963.

[15] K. Slinkard and V. L. Singleton, "Total phenol analysis: automation and comparison with manual methods," American Journal of Enology and Viticare, vol. 28, pp. 49-55, 1967.

[16] G. Miliauskas, P. R. Venskutonis, and T. A. van Beek, "Screening of radical scavenging activity of some medicinal and aromatic plant extracts," Food Chemistry, vol. 85, no. 2, pp. 231-237, 2004.

[17] H. Fan, T. Zheng, Y. Chen, and G. Yang, "Chemical constituents with free-radical-scavenging activities from the stem of Fissistigma polyanthum," Pharamacognosy Magazine, vol. 8, no. 30, pp. 98-102, 2012.

[18] A. Yildirim, A. Mavi, and A. A. Kara, "Antioxidant and antimicrobial activities of Polygonum cognatum Meissn extracts," Journal of the Science of Food and Agriculture, vol. 83, no. 1, pp. 64-69, 2003.

[19] I. F. F. Benzie and J. J. Strain, "Ferric reducing/antioxidant power assay: direct measure of total antioxidant activity of biological fluids and modified version for simultaneous measurement of total antioxidant power and ascorbic acid concentration," Methods in Enzymology, vol. 299, pp. 15-27, 1999.

[20] H. Tamura and A. Yamagami, "Antioxidative activity of monoacylated anthocyanins isolated from Muscat Bailey A grape," Journal of Agricultural and Food Chemistry, vol. 42, no. 8, pp. 1612-1615, 1994.

[21] H. Ohkawa, N. Ohishi, and K. Yagi, "Assay for lipid peroxides in animal tissues by thiobarbituric acid reaction," Analytical Biochemistry, vol. 95, no. 2, pp. 351-358, 1979.

[22] D. J. Shapiro and V. W. Rodwell, "Regulation of hepatic 3hydroxy-3-methylglutaryl coenzyme A reductase and cholesterol synthesis," The Journal of Biological Chemistry, vol. 246, no. 10 , pp. 3210-3216, 1971. 
[23] J. A. Buege and S. D. Aust, "Microsomal lipid peroxidation," Methods in Enzymology, vol. 52, pp. 302-310, 1978.

[24] S. Arabshahi-Delouee, V. Devi, and A. Urooj, "Evaluation of antioxidant activity of some plant extracts and their heat, $\mathrm{pH}$ and storage stability," Food Chemistry, vol. 100, no. 3, pp. 1100$1105,2007$.

[25] S. Mandal, S. Yadav, S. Yadav, and R. K. Nema, "Antioxidants: a review," Journal of Chemical and Pharmaceutical Research, vol. 1, no. 1, pp. 102-104, 2009.

[26] V. K. Gupta and S. K. Gupta, "Plants as natural antioxidants," Natural Product Radiance, vol. 5, no. 6, pp. 326-334, 2006.

[27] S. Arabshahi-Delouee and A. Urooj, "Antioxidant properties of various solvent extracts of mulberry (Morus indica L.) leaves," Food Chemistry, vol. 102, no. 4, pp. 1233-1240, 2007.

[28] C.-C. Wong, H.-B. Li, K.-W. Cheng, and F. Chen, "A systematic survey of antioxidant activity of 30 Chinese medicinal plants using the ferric reducing antioxidant power assay," Food Chemistry, vol. 97, no. 4, pp. 705-711, 2006.

[29] L. J. Lizcano, M. Viloria-Bernal, F. Vicente et al., "Lipid oxidation inhibitory effects and phenolic composition of aqueous extracts from medicinal plants of colombian amazonia," International Journal of Molecular Sciences, vol. 13, no. 5, pp. 54545467, 2012.

[30] S. M. Zachariah, N. A. Aleykutty, V. Viswanad, S. Jacob, and V. Prabhakar, "In-vitro antioxidant potential of methanolic extracts of Mirabilis jalapa Linn," Free Radicals and Antioxidants, vol. 1, no. 4, pp. 82-86, 2011.

[31] P. V. Reddy, M. Sowmya, and A. Urooj, “Abrus precatorius leaves: antioxidant activity in food and biological systems, $\mathrm{pH}$ and temperature stability," International Journal of Medicinal Chemistry, vol. 2014, Article ID 748549, 7 pages, 2014.

[32] P. V. Reddy, A. Urooj, and A. Kumar, "Evaluation of antioxidant activity of some plant extracts and their application in biscuits," Food Chemistry, vol. 90, no. 1-2, pp. 317-321, 2005.

[33] E. H. Mansour and A. H. Khalil, "Evaluation of antioxidant activity of some plant extracts and their application to ground beef patties," Food Chemistry, vol. 69, no. 2, pp. 135-141, 2000.

[34] A. H. Azizah, N. M. Nik Ruslawati, and T. Swee Tee, "Extraction and characterization of antioxidant from cocoa by-products," Food Chemistry, vol. 64, no. 2, pp. 199-202, 1999.

[35] M. G. Miguel, "Antioxidant activity of medicinal and aromatic plants. A review," Flavour and Fragrance Journal, vol. 25, no. 5, pp. 291-312, 2010. 

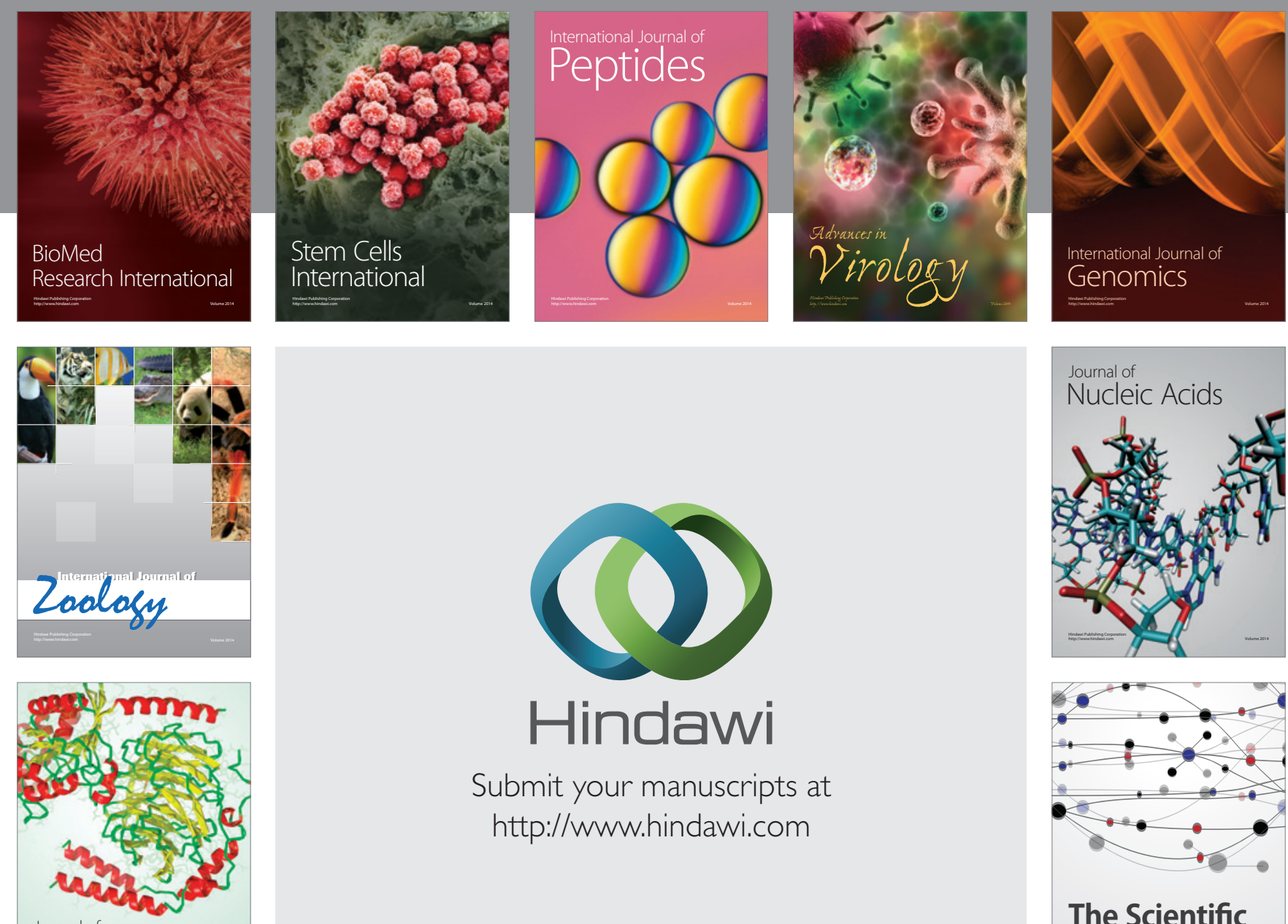

Submit your manuscripts at

http://www.hindawi.com

Journal of
Signal Transduction
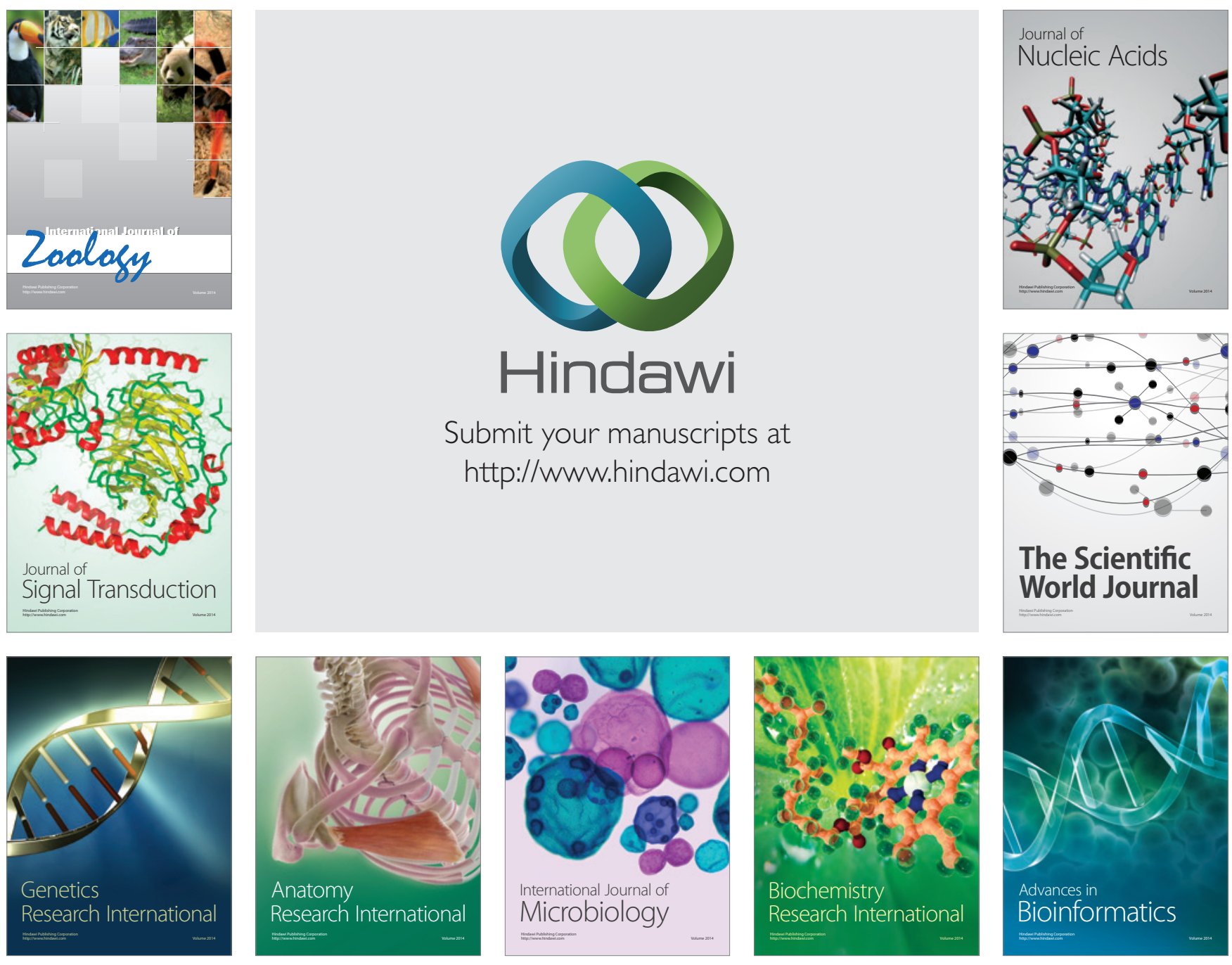

The Scientific World Journal
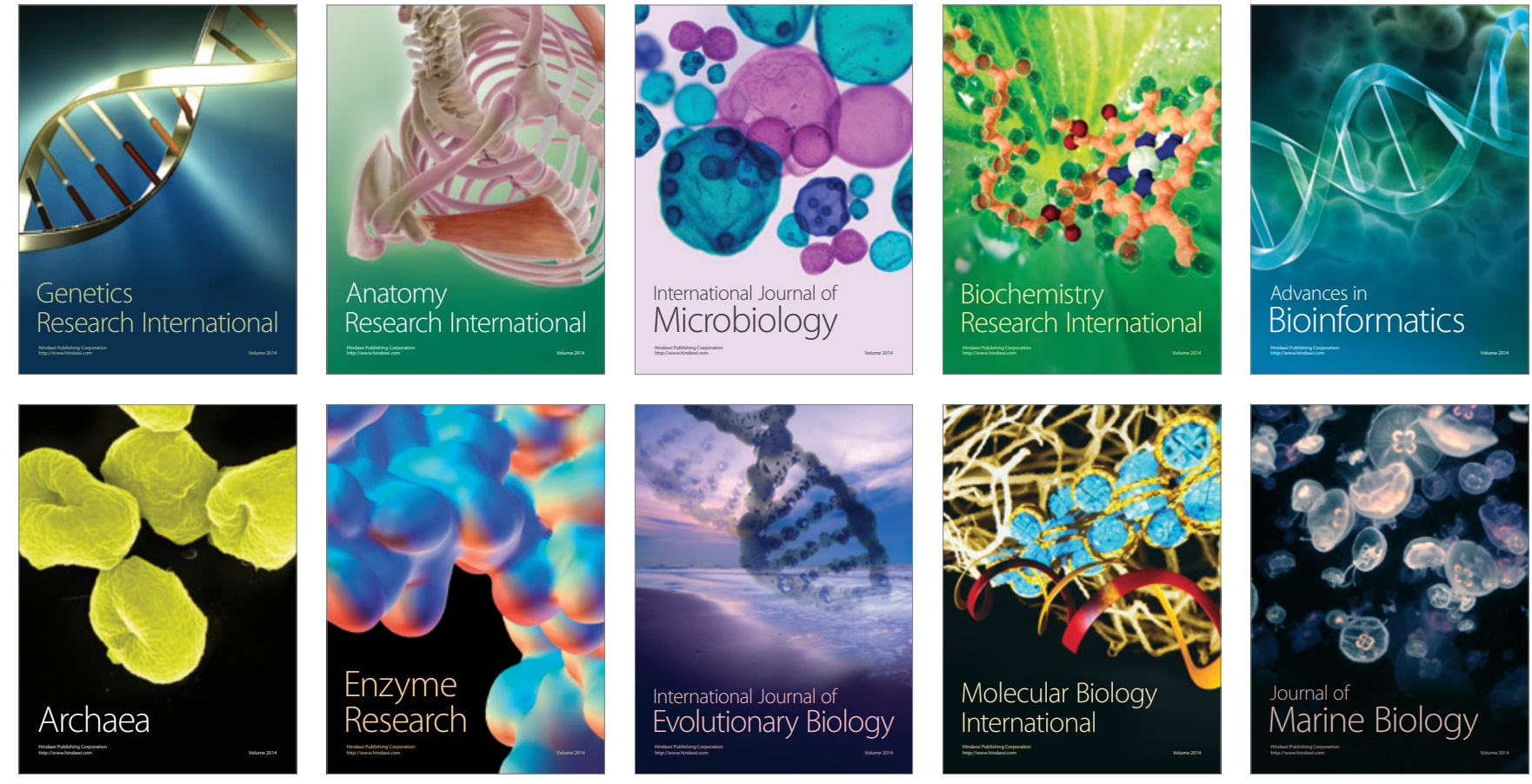